
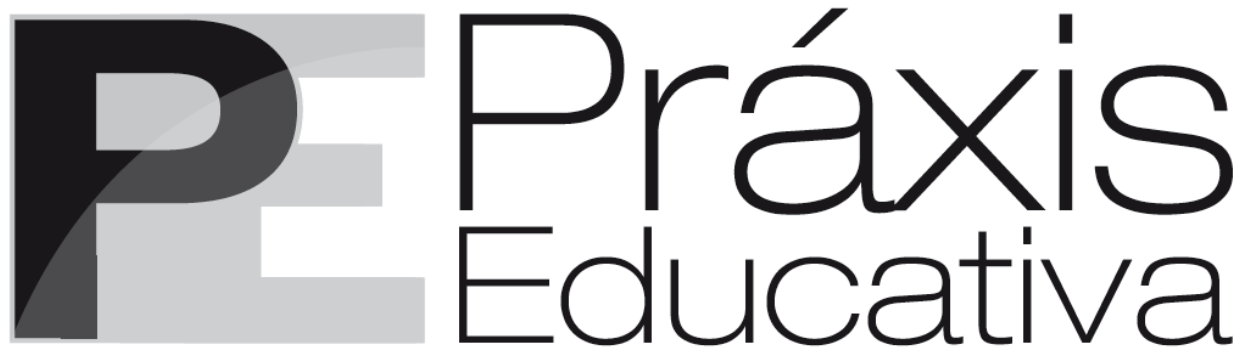

ISSN 1809-4309 (Versão online) DOI: 10.5212/PraxEduc.v.11i3.0015

\title{
Avaliações no currículo do primeiro ano do Ensino Fundamental: governo de professores/as e alunos/as e implementação do dispositivo de antecipação da alfabetização
}

\section{The evaluation in the elementary school first year curriculum: teachers' and students' guidance and the implementation of the literacy anticipation}

device

\author{
Evaluaciones en el currículo del primer año de la enseñanza fundamental: \\ gobierno de los profesores/as y alumnos/as y la aplicación del dispositivo \\ de anticipación de la alfabetización \\ Maria Carolina da Silva Caldeira*
}

\begin{abstract}
Resumo: Por meio de uma pesquisa que utilizou técnicas etnográficas articuladas à análise de discurso de inspiração foucaultiana, este artigo analisa os efeitos de avaliações em um currículo de uma turma de primeiro ano do Ensino Fundamental e mostra a lógica avaliativa em ação no currículo, que faz a avaliação assumir três formas: 1) avaliação para acompanhar a aprendizagem das crianças; 2) avaliação dos comportamentos infantis; 3) avaliações sistêmicas. Os resultados apontam que esses três modos de avaliar, com suas diferentes estratégias e práticas, conduzem os mais diferentes raciocínios no currículo investigado. A conclusão é de que são instituidas relações de poder-saber, governando alunos/as e docentes e auxiliando na implementação e operacionalização do dispositivo de antecipação da alfabetização.

Palavras-chave: Currículo. Avaliação. Alfabetização.
\end{abstract}

Abstract: Through the development of a study using ethnographic techniques allied to the Foucauldian discourse analysis, this paper analyzes the effects of evaluation in an elementary school first year curriculum and shows the evaluation logics in action in the curriculum, which gives the evaluation three formats: 1) evaluation to follow the children's learning process; 2) evaluation of children's behavior; 3) systemic evaluations. The results revealed that these three types of evaluation, with their different strategies and practices, lead to several different reasoning processes in the curriculum under investigation. The conclusion is that power-knowledge relations are established, guiding students and teachers and helping the implementation and operationalization of the literacy anticipation device.

Keywords: Curriculum. Evaluation. Literacy.

\footnotetext{
* Professora do Centro Pedagógico da Escola de Educação Básica e Profissional da Universidade Federal de Minas Gerais (UFMG). Doutoranda em Educação - FAE/UFMG. E-mail: <mariacarolinasilva@hotmail.com>.

** Professora da Faculdade de Educação da Universidade Federal de Minas Gerais (UFMG). E-mail: $<$ marlucyparaiso@gmail.com>.
} 
Resumen: En esta pesquisa se ha utilizado técnicas etnográficas articuladas a los análisis del discurso de inspiración foucaultiana, este artículo hace un análisis de los efectos de evaluaciones en un currículo de un grupo de primer año de la Enseñanza Fundamental y una muestra de la lógica evaluativa en acción el en currículo, que hace la evaluación asumir tres formas: 1) evaluación para acompañar el aprendizaje de los niños; 2) evaluación de los comportamientos infantiles; 3) evaluaciones sistémicas. Los resultados apuntan que esos tres modos de evaluar, con sus diferentes estrategias y prácticas, conducen los más diferentes raciocinios en el currículo investigado. La conclusión es que son instituidas relaciones de poder-saber, gobernando alumnos/as y docentes y auxiliando en la implementación y organización del dispositivo de anticipación de la alfabetización.

Palabras clave: Currículo. Evaluación. Alfabetización.

\section{Introdução}

Que influências a avaliação tem no currículo de uma turma de primeiro ano do Ensino Fundamental? Como os diferentes significados que a avaliação toma na educação contemporânea têm sido vividos no início da escolarização fundamental? Que saberes e conhecimentos são priorizados no currículo do primeiro ano em função da lógica avaliativa que vem sendo implantada nas escolas brasileiras nos últimos 20 anos? Que relações de poder são instauradas em função da avaliação desde o início da escolarização? De que forma apresenta-se a avaliação como algo desejável e necessário para as crianças de seis anos que agora frequentam o Ensino Fundamental? É em torno da inquietação gerada por tais perguntas que este artigo se organiza. Com base em uma investigação que articulou técnicas etnográficas com a análise de discurso de inspiração foucaultiana para investigar o dispositivo de antecipação da alfabetização, este artigo analisa os efeitos que a avaliação tem em um currículo de uma turma do primeiro ano do Ensino Fundamental da Rede Municipal de Belo Horizonte.

O currículo é aqui compreendido como um espaço privilegiado para experimentações, vivências e práticas que, sendo um espaço de ensino por excelência (PARAÍSO, 2011), disponibiliza modos de ser e estar no mundo, modos esses que ultrapassam as relações que se estabelecem na escola, deixando marcas complexas naqueles/as que os vivenciam (PARAísO, 2010a). Não se trata exclusivamente de um documento, mas das diferentes práticas que são proporcionadas aqueles/as que vivenciam o currículo. É nele que os saberes e conhecimentos se organizam, disputam espaço, estabelecem lutas e definem normas e padrões de conduta. Nele são vividos os conflitos culturais, políticos e discursivos que evidenciam como o currículo se constitui em um campo de lutas. Por ser um processo de seleção de um conjunto de saberes e conhecimentos, o currículo privilegia algumas experiências em vez de outras, processo esse marcado pelas relações de poder (SILVA, 2001). Em síntese, o currículo é compreendido neste artigo como "um discurso que, ao corporificar narrativas particulares sobre o indivíduo e a sociedade, nos constitui como sujeitos" (SILVA, 1995, p. 195).

O sujeito, por sua vez, é aqui entendido como uma produção. Ele é produzido por meio de discursos, relações de poder e técnicas de si. Ele é efeito de processos de subjetivação, que podem ser definidos como "as diversas maneiras pelas quais os indivíduos ou as coletividades se constituem como sujeitos" (DELEUZE, 1992a, p. 217). Esse processo de produção se dá porque "o sujeito não é uma substância" (FOUCAULT, 2004, p. 275). Por essa razão, ele precisa ser constantemente produzido. Nesse sentido, Deleuze (1992b) afirma que "sim, existem sujeitos: são grãos dançantes na poeira do visível, e lugares móveis num murmúrio anônimo. O sujeito é sempre uma derivada. Ele nasce e se esvai na espessura do que se diz, do que se vê"

Práxis Educativa, Ponta Grossa, p. 795-811, v. 11, n. 3, set./dez. 2016 Disponível em: < http://www.revistas2.uepg.br/index.php/praxiseducativa > 
(DELEUZE, 1992b, p. 133). Entender o currículo como envolvido na produção de sujeitos implica, portanto, analisar os discursos que ali circulam, as relações de poder-saber estabelecidas, as técnicas de si implementadas e as posições de sujeito definidas.

A pesquisa que dá base a este artigo procurou investigar esses elementos. Ela foi realizada em uma turma de primeiro ano do Ensino Fundamental da Rede Municipal de Belo Horizonte. A turma - composta por 26 alunos/as e sua professora - foi acompanhada no decorrer do ano de 2013, com o objetivo geral de analisar os efeitos que o dispositivo de antecipação da alfabetização tem no currículo, nos/as alunos/as e nas docentes. ${ }^{1}$ Dispositivo é entendido aqui com base nas constribuições de Michel Foucault, que o define como "um conjunto decididamente heterogêneo que engloba discursos, instituições, organizações arquitetônicas, decisões regulamentares, leis, medidas administrativas, enunciados científicos, proposições filosóficas, morais, filantrópicas" (FOUCAULT, 2000, p. 244), com vistas à produção de processos de subjetivação. O dispositivo, em uma perspectiva foucaultiana, dispõe diferentes elementos, discursivos e não-discursivos, organizando-os para produzir sujeitos de determinado tipo. No caso do dispositivo de antecipaşão da alfabetização investigado, considera-se que ele aciona saberes, conhecimentos, normas, regras, exercícios, atividades, materiais, tudo isso para garantir a produção de uma criança que esteja alfabetizada o quanto antes, preferencialmente ao final do primeiro ano do Ensino Fundamental. Entre os diferentes elementos colocados em funcionamento por esse dispositivo, a avaliação assume papel central, já que é por meio dela que se pode saber se a alfabetização foi alcançada.

A avaliação é, pois, um dos elementos que auxilia na implementação e operacionalização do dispositivo de antecipação da alfabetização. No currículo investigado, a avaliação assume três formas principais. Uma delas trata de acompanhar a aprendizagem das crianças no que se refere à alfabetização. Nesse momento, ela se aproxima de dois discursos que têm bastante força no Brasil desde os anos 1980: o discurso da psicogênese da língua escrita e o discurso da avaliação mediadora, que objetiva garantir o acompanhamento das aprendizagens dos/as alunos/as por meio de um processo que se desenvolve "a partir da análise das hipóteses formuladas pelo educando, suas ações e manifestações visando essencialmente ao entendimento" (HOFFMANN, 2006a, p. 61). Além disso, a avaliação também opera como uma espécie de técnica de si, no sentido foucaultiano, qual seja: técnicas que permitem aos indivíduos "operarem um certo número de operações sobre os seus corpos, sobre as suas almas, sobre o seu próprio pensamento, sobre a sua própria conduta, e isso de tal maneira a transformarem-se a eles próprios" (FOUCAULT, 1993, p. 207). Assim, é comum no currículo investigado que os/as alunos/as sejam convidados/as a avaliarem seu próprio comportamento e suas atividades para, com base nessa avaliação, realizarem um processo de reflexão e mudança de suas ações. Por fim, a avaliação é vivida também como um processo externo à escola, por meio do qual testes são enviados pelos órgãos governamentais para as escolas a fim de medir como tem se dado a aprendizagem das crianças e o processo de ensino das docentes. Esse processo é nomeado de avaliação sistêmica, ou seja, aquelas efetuadas pelos órgãos centrais dos sistemas de ensino para monitorar o processo de ensino nas escolas (CATANI; GALLEGO, 2009).

Argumentamos que a avaliação é um dos elementos que nesse currículo visa à condução de condutas infantis (que devem se comportar conforme normas previamente estabelecidas) e docentes (já que essas também devem conduzir sua conduta para oportunizar certas aprendizagens). Esse processo faz com que o dispositivo de antecipação da alfabetização no primeiro ano do Ensino Fundamental ganhe forças e opere de forma cada vez mais condundente. Assim, consideramos que a avaliação é um instrumento para o governo de infantis e docentes no

\footnotetext{
1 Ao longo da pesquisa que teve esse objetivo geral, a avaliação destacou-se como importante elemento no entendimento das relações de poder que ali se estabeleciam. Por essa razão, apresentamos esse recorte neste artigo.
}

Práxis Educativa, Ponta Grossa, p. 795-811, v. 11, n. 3, set./dez. 2016 Disponível em: <http://www.revistas2.uepg.br/index.php/praxiseducativa> 
currículo. Governo é definido com base em Michel Foucault (1995) como um modo de "estruturar o eventual campo de ação dos outros" (FOUCAULT, 1995, 244). As avaliações significadas dessa forma estruturam o currículo na medida em que definem que conhecimentos e saberes devem ser priorizados, que práticas são mais adequadas e que objetivos se espera alcançar. Estruturam também o campo de ação das crianças de seis anos que devem demonstrar aquilo que já aprenderam e também se comportar conforme as normas estabelecidas pela escola. Definem, ainda, como as professoras devem organizar suas práticas a fim de atingir o objetivo de garantir que todos/as os/as alunos/as estejam alfabetizados/as ao final do primeiro ano. Para desenvolvimento desse argumento, este artigo se divide em três partes, cada uma delas analisando um dos modos como a avaliação é vivida no currículo do primeiro ano do Ensino Fundamental.

\section{O acompanhamento constante das aprendizagens infantis: a psicogênese da escrita e a avaliação mediadora no currículo investigado}

Ditados, exercícios em duplas e individuais, correção do caderno, dever de casa: esses são instrumentos utilizados para verificar como os/as 26 alunos/as da turma investigada se desenvolvem no que concerne à alfabetização. Por ser essa a aprendizagem buscada com mais afinco no currículo investigado, as práticas de ensino e também de avaliação se voltam para ela com maior interesse. Por esse motivo, exercícios nos quais fosse necessário demonstrar o que já se tinha aprendido sobre alfabetização são realizados constantemente. Na turma investigada, o discurso da psicogênese da língua define como deve ser o desenvolvimento da alfabetização. Ele opera nesse currículo, organizando saberes, conhecimentos e práticas que objetivam fazer com que a criança se alfabetize. Também serve como critério para a avaliação realizada em sala de aula.

O discurso da psicogênese da lingua escrita refere-se ao conjunto de saberes, conhecimentos, práticas, técnicas e exercícios advindos da pesquisa desenvolvida nos anos 1980 por Ana Teberosky e Emilia Ferreiro (FERREIRO; TEBEROSKY, 1985). Essa pesquisa construiu "uma explicação dos processos e das formas mediante as quais a criança consegue aprender a ler e a escrever" (FERREIRO; TEBEROSKY, 1985, p. 17). Por meio de pesquisas realizadas por dois anos com crianças de quatro a seis anos de diferentes classes sociais na Argentina, as autoras demonstram que processos cognitivos estão na base da aprendizagem da leitura e da escrita. Usando conhecimentos da psicologia genética piagetiana, elas realizam uma série de testes com crianças, nos quais tentam compreender como elas conceptualizam a escrita.

O discurso da psicogênese da língua escrita defende que "a escrita infantil segue uma evolução surpreendentemente regular, através de diversos meios culturais, de diversas situações educativas, de diversas línguas" (FERREIRO, 1985, p. 10). Segundo essa perspectiva, essa evolução se inicia com um primeiro grande período, no qual as crianças aprendem a distinguir entre o modo de representação icônico (desenhos) e o não-icônico (FERREIRO, 1985). No momento seguinte, para esse discurso, são criados "mecanismos progressivos de controle" sobre as variações, que fazem com que escritas sejam diferentes (FERREIRO, 1985), ou seja, as crianças desenvolvem estratégias, como a quantidade mínima de letras e a variação dessas letras, para definir escritas diferentes entre si. Por fim, ocorre o processo de "fonetização da escrita", quando as crianças compreendem que a língua escrita é uma representação - arbitrária - dos sons (FERREIRO; TEBEROSKY, 1985). De modo geral, as hipóteses infantis sobre a língua são nomeadas como pré-silábica - período anterior à fonetização -, silábica - na qual a criança usa uma sílaba para cada letra -, silábica-alfabética - quando há alternância entre usar uma letra para cada sílaba e sílabas inteiras - e alfabética - momento em que a escrita torna-se convencional (FERREIRO, 1985; MORAIS, 2012a). 
No currículo investigado, esses conceitos são utilizados como normas para definir como as crianças se desenvolvem. Embora existam questionamentos na contemporaneidade ao discurso da psicogênese da língua escrita (MORAIS, 2012a), no currículo investigado ele adquire caráter de verdade. Seus princípios funcionam, assim, como parâmetro para definir quem é a criança alfabetizada. Aquela que atingir, no mínimo, uma escrita silábico-alfabética é considerada alfabetizada. Assim, neste artigo, tomando como base os critérios estabelecidos na turma investigada, consideramos a alfabetização como o momento em que as crianças eram capazes de escrever seguindo padrões convencionais de escrita que pudessem ser compreendidos por outros/as alfabetizados/as. Porém, como se entende o currículo como um discurso, defende-se que essa criança alfabetizada não é um dado natural, mas uma produção discursiva. Afinal, discursos "são práticas que formam sistematicamente os objetos de que falam" (FOUCAULT, 1972, p. 64).

Ao definir as crianças de acordo com esses critérios, o currículo investigado, que opera com os ditos do discurso da psicogênese da língua escrita, produz posições de sujeito que precisam ser ocupadas pelas crianças para que seus modos de escrever sejam reconhecidos na escola. A criança pré-silábica, silábica, silábico-alfabética ou alfabética é uma produção desse discurso. Por meio de procedimentos variados, o currículo dá visibilidade a determinadas práticas que permitem nomear as crianças dessa forma. As práticas de avaliação assumem papel central nesse processo de construção discursiva da criança alfabetizada. É por meio delas que se define cada uma das posições especificadas anteriormente. Assim, é após um processo avaliativo detalhado que se pode afirmar que "Evellyn ${ }^{2}$ está na hipótese pré-silábica da escrita" ou que "Brenda avançou no processo de escrita e encontra-se na hipótese silábica-alfabética" . Para colocar os/as alunos/as nessa posição, é preciso monitorar constantemente sua aprendizagem, verificando como tem sido o desenvolvimento da criança conforme as normas estabelecidas nesse currículo.

Entre os exercícios avaliativos mais utilizados para a avaliação infantil na turma investigada estão os ditados. As práticas de ditado, já sabemos, estão entre as mais antigas praticadas pela escola (CHARTIER, 2010). Por meio delas, busca-se "transformar um texto oral em texto escrito" (CHARTIER, 2014, s.p). Na turma investigada, eram ditadas palavras de um mesmo campo semântico (listas de brinquedos, comidas, frutas, animais), listas de palavras que têm a mesma letra (começadas por $\mathrm{C}$, por exemplo, ou que tenham $\mathrm{CH}$ e X), parlendas e outros textos cantados. No encontro dos ditados com o discurso da psicogênese da língua escrita, todavia, há uma alteração no modo como esses ditados vão ser significados. Não se trata de uma prática para verificar a ortografia dos/as alunos/as, prática essa que fez com que o ditado fosse "condenado como uma 'máquina de fabricar erros', porque ele pede aos alunos para inventar a ortografia de palavras que eles desconhecem (CHARTIER, 2010, p. 7). O ditado serve, nos dizeres da professora investigada, para verificar "como a criança está pensando sobre a escrita" (Diário de campo, 07/05/2013). Ele vincula-se, então, a um dos pressupostos das teorias psi: a ideia de que a criança é ativa no processo de produção do conhecimento. Teorias psi referem-se a um conjunto de estudos e práticas que, na contemporaneidade, utilizam-se da psicologia para afirmarem-se como verdadeiras. Essas teorias estão no centro de variadas práticas cotidianas atuais, como aponta Rose (2001). A psicogênese da língua escrita pode ser considerada como integrante das teorias psi.

\footnotetext{
2 Respeitando as regras do Comitê de Ética na Pesquisa e os acordos feitos com os/as pesquisados/as, todos os nomes aqui utilizados são fictícios.

3 Informações registradas pela professora e posteriormente digitadas na ficha de avaliação de cada criança que foi entregue para os familiares ao final do segundo trimestre.
}

Práxis Educativa, Ponta Grossa, p. 795-811, v. 11, n. 3, set./dez. 2016 Disponível em: <http://www.revistas2.uepg.br/index.php/praxiseducativa> 
Nesse raciocínio, considera-se necessário entender como a criança está pensando sobre a escrita para estimulá-la a aprender mais rápido e melhor. Durante uma das práticas de ditado, afirma-se que é preciso "deixar o colega pensar", pois o objetivo do ditado é "ver se o colega sabe sem dar dica" (Diário de campo, 25/04/2013). Quando as crianças questionam a professora sobre como escrever determinada palavra, ela diz: "na hora do ditado, a professora esquece tudo. Você que tem que pensar" (Diário de campo, 22/06/2013). Há também procedimentos de repreensão daqueles/as que tentam ajudar seus/suas colegas durante o ditado, como quando se afirma: "se você o ajudar, a professora não vai saber o que ele não sabe. A boa professora é a que conta tudo e não deixa o menino pensar?” (Diário de campo, 28/09/2013).

A prática do ditado - que funciona no currículo investigado como uma prática avaliativa produz e demanda a posição de sujeito criança que pensa. Para se alfabetizar, é necessário pensar sobre a escrita, refletir sobre o uso de determinadas letras, prestar atenção no som de cada palavra e escolher a letra correta a ser usada. A criança é ativa nesse processo, porém, sua atividade referese apenas ao ato de pensar. Ela não deve ser ativa contando para outras crianças como ela está pensando. Estabelece-se, assim, nesse currículo uma norma segundo a qual o pensar sobre a escrita deve ser individual e não compartilhável.

Essa norma tem um duplo efeito: por um lado, normatiza os comportamentos infantis esperados pela escola de Ensino Fundamental, que incluem ficar calado durante o ditado; por outro lado, estabelece o padrão normal de desenvolvimento das crianças, quando define em que lugar ela se encontra na "fila de desenvolvimento" estabelecida pela psicogênese da língua escrita. A norma se caracteriza como a instituição do poder no processo de construção de modos de subjetivação (SILVA, 2000, p. 83). Ela define aquilo que deve e não deve ser vivido. Por isso, vincula-se aos processos de governo dos outros (FOUCAULT, 1997), já que um padrão externo é apresentado às crianças, visando à condução de suas condutas. Nesse processo, a professora assume a posição de condutora dos modos de pensar infantis e também dos comportamentos esperados no Ensino Fundamental.

Não existe, todavia, relação de poder que se estabeleça sem resistência (FOUCAULT, 1995). A norma que define que o pensar sobre a escrita deve ser individual é constantemente revogada nesse currículo. Se o conhecimento psi parte do princípio de que cada criança deve expressar o seu saber individual, o modo particular como está pensando, os/as alunos/as do currículo investigado constroem outras práticas ao entrar em contato com esse conhecimento. Assim, nas práticas de ditado, há várias transgressões, como se pode ver no episódio descrito a seguir:

Durante o ditado, Julia fala as letras para Evellyn Rezende. Karen pega seu caderno e tenta olhar a escrita das palavras. Evellyn Silva olha para o alfabeto afixado no alto da sala e o recita em voz alta para saber que letra usar. Nicolas olha a atividade de Mateus, que a esconde. A professora percebe que Julia está falando as letras para Evellyn Rezende e afasta as duas meninas. Apesar disso, elas ainda tentam dialogar (Diário de campo, 30/08/2013). ${ }^{4}$

As transgressões assumem variadas formas. Podem se expressar: 1) na tentativa de observação da tarefa de outro/a colega; 2) na busca de informações no caderno ou em outros elementos presentes na sala de aula; 3) pela conversa com outro/a alun. Se no currículo orientado pelos conhecimentos da psicogênese da língua escrita prega-se uma individualização do saber, os/as

\footnotetext{
${ }^{4}$ Utilizamos uma fonte diferente para diferenciar os trechos do diário de campo de citações convencionais com recuo.
}

Práxis Educativa, Ponta Grossa, p. 795-811, v. 11, n. 3, set./dez. 2016 Disponível em: <http://www.revistas2.uepg.br/index.php/praxiseducativa> 
infantis, ao vivenciarem práticas orientadas por esse conhecimento, tentam coletivizar seus saberes, ensinando-se mutuamente. Essas transgressões não impedem, todavia, que a prática do ditado seja realizada cotidianamente no currículo investigado.

A presença constante dos ditados na turma investigada vincula-se não apenas ao discurso da psicogênese da língua escrita, mas também à ideia de que é preciso monitorar constantemente o aprendizado da criança. Nesses momentos, opera no currículo investigado o discurso da avaliaşão mediadora. A avaliação mediadora - também nomeada de avaliação formativa - "acontece ao longo do processo, com o objetivo de reorientá-lo” (FERNANDES; FREITAS, 2007, p. 20). É possível perceber a presença desse discurso, já que as atividades avaliativas voltadas para a alfabetização servem para a docente "acompanhar as hipóteses que as crianças vêm formulando a respeito de determinados assuntos, em diferentes áreas de conhecimento, de forma a exercer uma ação educativa que lhes favoreça" (HOFFMANN, 2006b, p. 75). A avaliação, dessa maneira, tem o duplo objetivo de mapear as hipóteses infantis, com base nos conhecimentos da psicogênese da língua escrita, e de reorientar a prática docente, que, a partir dos resultados, decide que atividades são proporcionadas às crianças na sequência. Os resultados da avaliação servem, então, para que a professora conduza sua prática com as crianças.

Assim, de modo geral, as práticas de ditado são seguidas por uma correção individual feita pela docente, que assinala as escritas incorretas e tenta compreender, com base no modo como as crianças escrevem, quais suas hipóteses sobre a escrita. As informações produzidas pela professora são anotadas em seu caderno de planejamento. Como a prática do ditado é realizada semanalmente, novas informações sobre os/as alunos/as são produzidas e constituem um saber sobre as crianças que serve para direcionar as práticas em sala de aula, pois "quanto mais se conhece, melhor se educa" (CORAZZA, 2001, p. 34).

Esse saber é utilizado nos momentos de avaliação somativa, aqueles que "tem como objetivo estabelecer informações confiáveis dos resultados obtidos ao final de um processo de ensino aprendizagem" (JORBAN; SANMARTIN, 2003, p. 32). Ou seja, ainda que inspirados no discurso da avaliação mediadora, os resultados obtidos são utilizados para, ao final do processo, classificar os avanços e dificuldades das crianças. Esse saber é, então, utilizado para exercer poder sobre os/as alunos/as. Isso não é de se espantar, já "não há saber neutro. Todo saber é político" (MACHADO, 2000, p. XXI), ou seja, não há saber que não se articule, de alguma forma, com as relações de poder (FOUCAULT, 1999). Assim, as informações sobre os/as alunos/as produzidas e registradas constituem-se em um modo de exercer poder sobre eles/as.

Além de anotar essas informações, os ditados também são corrigidos coletivamente para que as crianças tenham nova oportunidade de pensar sobre a escrita daquelas palavras. A avaliação acaba por definir como as práticas devem ser desenvolvidas no currículo. Esse momento de correção coletiva é conduzido pela docente que pede que algumas crianças falem como pensam que determinada palavra deve ser escrita. Cabe registrar que esse é um exercício comum em práticas orientadas pelo discurso da psicogênese da lingua escrita. Nessas práticas, "sempre que possível, a revisão das atividades é feita no quadro, coletivamente, seguindo processo de análise de cada parte da palavra, até que as crianças descubram sua escrita convencional" (SÁ, 2010 , p. 204). Ao contrário do que ocorre no primeiro momento da prática do ditado, aqui as crianças podem interagir e "ajudar o colega". Assim, mais um dos elementos do discurso da avaliação mediadora está presente no currículo. Considera-se que "a avaliação é 'movimento', é ação e reflexão. $\mathrm{Na}$ medida em que as crianças realizam suas tarefas, efetivam muitas conquistas: refletem sobre suas hipóteses" (HOFFMANN, 2006a, p. 52). O discurso da avaliação mediadora articula-se ao da psicogênese da escrita para fortalecer a posição de sujeito criança que pensa.

Práxis Educativa, Ponta Grossa, p. 795-811, v. 11, n. 3, set./dez. 2016 Disponível em: <http://www.revistas2.uepg.br/index.php/praxiseducativa > 
$\mathrm{Na}$ produção da criança que pensa, o erro adquire um caráter importante. Na perspectiva do discurso da avaliação mediadora, o erro é "visto como algo dinâmico, como caminho para o avanço (LUCKESI, 1997, p. 58). Ele é compreendido como algo construtivo, por "considerar que o conhecimento produzido pelo educando, num dado momento de sua experiência de vida, é um conhecimento em processo de superação" (HOFFMAN, 2006a, p. 56). Isso fica evidente no currículo investigado, em situações como a seguinte:

A professora entrega os ditados corrigidos para os/as alunos/as para que façam a correção coletiva no quadro. Adryan pega a sua folha e pede para apagar o que fez. O menino fica triste porque "errou todas as palavras". A professora diz: “Não está errado. É o jeito que você sabe. Eu já consigo ler o que você escreveu. Vai melhorar ainda". Apesar da explicação, o menino continua desejando apagar o ditado. (Diário de campo, 13/08/2013).

Ainda que se incentivem os modos como a criança pensa, circula nesse currículo, a ideia de que existe um padrão a ser alcançado. "O erro é visto e compreendido de forma dinâmica, na medida em que contradiz o padrão para, subsequentemente, possibilitar uma conduta nova em conformidade com o padrão ou mais perfeita que esse" (LUCKESI, p. 1997, p. 58). Errar na perspectiva do discurso da avaliação mediadora significa criar uma hipótese que contraria o padrão, mas ao mesmo tempo, deve ser incentivado um processo em que o/a aluno/a caminhe em relação a esse padrão. É o que se infere quando a docente afirma que o aluno "vai melhorar ainda". A criança é vista aqui como um ser em falta (CORAZZA, 1995). Falta a ela ainda aquilo que será necessário para ser considerada plenamente alfabetizada. Mesmo que se console o aluno Adryan dizendo-lhe que não se trata de um erro no sentido comum, há insatisfação por não se estar ainda no padrão esperado.

Esse padrão é a alfabetização que pode ser medida pelo número de palavras corretas em um ditado. Ele é assumido pelas crianças, que operam com a noção de que precisam se alfabetizar o quanto antes, afastando-se do erro e rechaçando-o quando ele ocorrer. O discurso da avaliação formativa que considera o erro como elemento produtivo entra, assim, em conflito com as demandas do dispositivo de antecipação da alfabetização que faz com que as crianças aprendam a desejar se alfabetizar o quanto antes. O currículo - como campo de luta e disputas - aciona diferentes elementos que, às vezes, vão a direções opostas na formação de posições de sujeito. Assim, por um lado, demanda-se a criança que pensa, por outro, produz-se a criança alfabetizada o quanto antes. As disputas discursivas que se estabelecem mostram os conflitos da avaliação no contexto do primeiro ano do Ensino Fundamental.

De modo semelhante, a avaliação estabelece padrões que vão além das hipóteses infantis. $\mathrm{Na}$ escola investigada, existem momentos de entrega de resultados para as famílias, por meio dos boletins $^{5}$. Esses boletins são produzidos com base nas informações produzidas pela avaliação mediadora e definem conceitos para as crianças. Esses conceitos servem, em alguns momentos, para criar hierarquias entre os/as alunos/as. Há, dessa forma, uma disputa entre os preceitos da avaliação mediadora (que consideram que o processo é mais importante do que o produto) e aqueles estabelecidos pela avaliação somativa, que tem como objetivo "estabelecer balanços dos resultados obtidos ao final de um processo de ensino-aprendizagem" (JORBA; SANMARTI, 2003, p. 32). Essas disputas são sentidas pelas crianças. Em certo momento, uma delas diz para uma das

\footnotetext{
${ }^{5}$ Os boletins são instrumentos de comunicação com as famílias a respeito dos resultados escolares dos/as alunos/as. Durante muitos anos, eles não foram utilizados na $\mathrm{PBH}$, que usava relatórios descritivos para informar os resultados dos/as estudantes. Foram retomados em 2010 e continham conceitos que iam de A (100 a 90\% de aproveitamento) até $\mathrm{F}$ (menos de $50 \%$ ).
}

Práxis Educativa, Ponta Grossa, p. 795-811, v. 11, n. 3, set./dez. 2016 Disponível em: <http://www.revistas2.uepg.br/index.php/praxiseducativa > 
pesquisadoras que "quer ter apenas A no boletim igual à Yasmin" (Diário de campo, 16/09/2013). Nesse momento, a aluna faz - com base nos valores estabelecidos por um processo de avaliação - uma autoavaliação do seu comportamento e do seu desempenho na escola para se adequar a determinada norma. São esses critérios de autoavaliação estabelecidos no currículo que analisamos no próximo tópico.

\section{Autoavaliação: técnica de si e constituição de sujeitos no currículo do primeiro ano}

Avaliar os resultados de suas atividades e avaliar o seu comportamento são dois procedimentos exigidos das crianças no primeiro ano do Ensino Fundamental. Elas precisam aprender a se comportar e a julgar se estão conseguindo ou não cumprir aquilo que delas se espera nesse nível de escolarização. Por essa razão, a autoavaliação é acionada nesse currículo como uma técnica de si (FOUCAULT, 1993), ou seja, como uma técnica que os/as alunos/as precisam operar sobre si mesmos, refletindo sobre o que fizeram ou deixaram de fazer com o objetivo de melhorar seu desempenho (HOFFMANN, 2006a) e para se tornarem sujeitos de determinado tipo. O sujeito que se pretende formar por meio dessa técnica é o/a aluno/a bem-comportado/a, que sabe julgar seus comportamentos e seguir as normas estabelecidas no currículo escolar.

A autoavaliação não toma, no currículo investigado, aspectos formais. Ela não é, por exemplo, uma avaliação escrita. Também não há uma periodicidade como acontecia na prática do ditado. Pelo contrário, ela é, na maior parte das vezes, realizada sem um planejamento anterior. $\mathrm{O} / \mathrm{a}$ aluno/a é chamado pela professora individualmente para refletir sobre o que fez, como quando a professora chama Luiz para que ele observe a ilustração que fez de uma parlenda e diz: "avalia o seu desenho! Você acha que ficou bom?" O menino olha e diz que não. A professora pergunta por que não ficou bom. Ele fala: "eu fiz correndo pra brincar." A professora continua: "e o que você pode fazer pra ele ficar melhor?". Ele diz que pode colorir e desenhar mais coisas (Diário de campo, 29/07/2013).

Assim como ocorre com a prática do ditado, a autoavaliação pode ser compreendida como uma prática proporcionada pelo discurso da avaliação mediadora. Isso porque para realizar práticas de avaliação mediadora é necessária a "utilização de instrumentos de avaliação diferenciados, [como a] auto-avaliação que leva a uma auto-reflexão e maior responsabilidade sobre sua própria aprendizagem" (FERNANDES; FREITAS, 2007, p. 34). No trecho relatado anteriormente fica perceptível a necessidade de levar o aluno a responsabilizar-se pela sua aprendizagem. Espera-se que o/a aluno/a aprenda a julgar sua produção - e também a si mesmo - para, assim, tornar-se o tipo de aluno que esse currículo pretende produzir. Ele/a precisa avaliar suas atividades para produzir sobre si determinado comportamento, afastando-se daquele comportamento considerado inadequado.

A autoavaliação implica, pois, um duplo processo. No primeiro deles, é preciso reconhecer aquilo que se é. Em seguida, é necessária uma "recusa do eu, o romper consigo próprio" (FOUCAULT, 1993, p. 215) para se tornar alguém diferente. Nesse processo de romper consigo, é preciso que o/a aluno/a já dê indícios daquilo que ele deve tornar-se, pois o alguém que a "pessoa constrói quando se olha, se diz, se narra ou se julga está implicado naquilo que a pessoa pode e deve fazer consigo mesma" (LARROSA, 1994, p. 82). Já é preciso, então, mostrar aquilo que se pretende ser. É o que se nota no exemplo acima em que a docente, assumindo mais uma vez a posição de condutora, indica como Luiz deve proceder para ser o aluno bem-comportado que a escola espera.

De modo geral, a autoavaliação serve, nesse currículo, para que os/as alunos/as avaliem seus comportamentos. Mais do que uma forma de avaliar a aprendizagem propriamente dita, ela é 
usada para julgar "aspectos morais, constituidores de uma ontologia-escolar" (CORAZZA, 1996, p. 57). Assim, várias vezes a docente interrompe alguma atividade ou explicação para dizer: "vamos avaliar o comportamento da turma agora. Vocês acham que está legal?" (Diário de campo, 02/08/2013), ou "vamos avaliar as duplas para ver quem deu conta e quem não deu. $\mathrm{Na}$ hora que eu for avaliar, na parte do boletim que tem um campo de trabalho em grupo, eu vou colocar as duplas que funcionaram e as que não funcionaram" (Diário de campo, 28/09/2013).

Essa postura já indica certo pressuposto sobre o que se deve avaliar. Afinal, raramente se interrompe a aula para fazer uma autoavaliação coletiva quando tudo está saindo bem, isto é, quando todos/as estão se comportando da forma considerada adequada naquele currículo. Geralmente, isso ocorre quando as regras não estão sendo seguidas. Assim, a docente assume a posição daquela que está "de posse de uma grade (visível ou invisível) de comportamentos e atitudes" (CORAZZA, 1996, p. 55) que define aquilo que deve ser observado nas autoavaliações. As conversas, o levantar fora de hora, as brincadeiras, são elementos que precisam ser avaliados pelas crianças para julgar-se. Após esse julgamento coletivo, é preciso abandonar tais comportamentos, seguindo o que se estabelece como princípios de comportamento.

Se considerarmos que "todo currículo quer mudar condutas. Todo currículo quer formar, produzir ou construir um tipo de sujeito" (PARAÍSO, 2010b, p. 47) fica fácil compreendermos porque a autoavaliação é acionada como técnica para moldar os/as alunos/as. Por meio dela, espera-se que o currículo atue na conduta de cada criança, transformando-a no/a aluno/a que se espera no Ensino Fundamental. Para isso, é preciso deixar de lado certas marcas que historicamente foram atribuídas às crianças (como o gosto pela brincadeira e as conversas) para se tornar um aluno/a que frequenta esse nível de ensino. Nele não são mais permitidas conversas fora de hora. Nesse raciocínio, também não se pode ficar de pé o tempo todo. Porém, isso não deve apenas ser dito pela docente. Para o raciocínio que ali opera, isso precisa ser discutido e refletido por aqueles/as que vivenciam o currículo do primeiro ano do Ensino Fundamental. Além disso, autovaliar-se para garantir seu bom comportamento, está envolvido com a implementação do dispositivo de antecipação da alfabetização, já que se considera, nesse currículo que, para aprender a ler e a escrever, é preciso deixar de lado a conversa, a brincadeira, a bagunça. Ser bem-comportado/a é um dos princípios estabelecidos nas práticas curriculares investigadas para ser capaz de se alfabetizar.

Dessa forma, "a avaliação nos coloca numa complexa e imensa rede de governamentos: permissões e interdições, estímulos e repressões, prêmios e castigos, sucessos e fracassos" (VEIGA-NETO, 2013, p. 168). Essa "rede de governamentos" refere-se aos diferentes elementos que servem para conduzir as condutas de determinada forma, garantindo determinadas características e atitudes. Desde o primeiro ano, os/as alunos/as aprendem que precisam se autoavaliar para evitar uma avaliação negativa em seu boletim e para terem sucesso na escola. Eles/a precisam mudar certas partes de si que não estão de acordo com o currículo vivido no Ensino Fundamental. Para isso, é preciso atuar no seu próprio autogoverno, acionando essas técnicas de si. Isso visa não somente ao desempenho de cada aluno/a, mas também à própria competência das docentes e da escola. Tal fato fica ainda mais visível quando se trata da avaliação sistêmica. Afinal, no processo que hoje vivemos, a avaliação vai muito além do espaço restrito da escola. Como afirma Veiga-Neto (2013, p. 166) "é a própria vida que foi colocada à mercê da fúria avaliatória". Somos, assim, convidados/as a avaliarmo-nos constantemente. Mas também somos avaliados por instâncias externas que objetivam, de forma ainda mais intensa, controlar os atos vivenciados nas escolas e salas de aula.

Práxis Educativa, Ponta Grossa, p. 795-811, v. 11, n. 3, set./dez. 2016 Disponível em: <http://www.revistas2.uepg.br/index.php/praxiseducativa> 


\section{As avaliações sistêmicas e a definição "do que ensinar"}

As avaliações sistêmicas "vêm ocupando um lugar central nas políticas em curso no país, constituindo-se em um dos elementos estruturantes de sua concretização" (SOUZA, 2002, p. 24). Desde os anos 1990, avaliações para diferentes níveis foram implantadas, com o objetivo de averiguar a qualidade na educação brasileira. No currículo investigado, as avaliações sistêmicas exercem um papel fundamental para a operacionalização do dispositivo de antecipação da alfabetização. Elas são apresentadas como uma das justificativas para que a alfabetização seja consolidada durante o primeiro ano. Afinal, "a alfabetização é até o final dos oito anos, mas as provas que chegam já são puxadas. A alfabetização já vai ser cobrada" (Entrevista com a professora, 16/05/2013). A professora demonstra sua preocupação com esse processo e, por isso, trava vários esforços para que as crianças estejam alfabetizadas, evitando, assim, baixo desempenho nas avaliações sistêmicas.

Especificamente na escola investigada há uma grande pressão em função dos resultados dessas avaliações. Isso se deve, em parte, ao bom resultado que essa escola teve em avaliações anteriores. Ela obteve o sexto melhor $\mathrm{IDEB}^{6}$ entre as escolas municipais de Belo Horizonte em 2011 e o maior da regional $7^{7}$ em que fica. Havia, assim, um desejo de que o índice permanecesse o mesmo ou melhorasse. Isso não é, no entanto, uma exclusividade dessa escola. Como mostra Paraíso (2010a, p. 140, destaques da autora) "há uma fome desenfreada das políticas educacionais contemporâneas por "bons desempenhos"'. Nessa luta para garantir que as escolas expressem uma melhoria na qualidade por meio do desempenho em testes padronizados, diferentes procedimentos são criados.

Na escola investigada, em julho de 2013, realizou-se uma reunião com as professoras dos três primeiros anos $\left(1^{\circ}\right.$ ciclo, conforme a nomenclatura da Rede Municipal de Belo Horizonte) para decidir o que seria feito em função da proximidade das avaliações sistêmicas que seriam realizadas com o $3^{\circ}$ ano e que definiriam o novo IDEB da escola. Nessa reunião houve posicionamentos contrários. Algumas professoras consideram que é preciso "fazer um treininho com os meninos do $3^{\circ}$ ano" (Fala da Professora Jacqueline $-3^{\circ}$ ano). Outras consideram isso desnecessário, já que "o resultado é reflexo do trabalho feito em sala" (Fala da Professora Roberta $-1^{\circ}$ ano). Apesar das posturas divergentes, convencionou-se que todos os dias, os/as alunos/as do $3^{\circ}$ ano deveriam resolver pelo menos uma questão no estilo múltipla escolha "para se familiarizarem com o jeito que as questões são formuladas" (Fala da Coordenadora Giovana, informações do Diário de campo, 12/07/2013).

O procedimento de treino é acionado nas turmas de $3^{\circ}$ ano a fim de garantir o bom desempenho da escola. Subjaz a essa prática, a ideia de que "quanto mais exercícios fizerem, melhor! Quanto mais repetição dos exercícios, mais facilidade poderão demonstrar nas avaliações" (PARAÍSO, 2010a, p. 141). Parece haver também uma subordinação do currículo à lógica avaliativa. Afinal, para garantir os bons resultados é preciso introduzir certas práticas no currículo. As professoras - para garantirem certo prestígio que sua escola ganhou - "acabam por se preocupar mais com o adestramento de seus alunos e a organizar o currículo a partir das habilidades exigidas nos testes" (MOREIRA, 1996, p. 14). A avaliação funciona, assim, como um mecanismo de governo das docentes que passam a conduzir suas práticas na escola a fim de manter os

\footnotetext{
6 Índice de Desenvolvimento da Educação Básica. Esse índice foi estabelecido pelo governo federal em 1997 e é "calculado a partir dos dados sobre aprovação escolar, obtidos no Censo Escolar, e médias de desempenho nas avaliações do Inep, o Saeb - para as unidades da federação e para o país, e a Prova Brasil - para os municípios" (Disponível em < http://portal.inep.gov.br/web/portal-ideb/o-que-e-o-ideb>. Acesso em 23/09/2015)

${ }^{7}$ A cidade de Belo Horizonte é dividida em nove regionais, que são responsáveis pela administração dos bairros, incluindo aí aspectos educacionais.
}

Práxis Educativa, Ponta Grossa, p. 795-811, v. 11, n. 3, set./dez. 2016 Disponível em: <http://www.revistas2.uepg.br/index.php/praxiseducativa> 
bons índices nas avaliações estatais. As avaliações sistêmicas atuam, também, modificando o currículo.

A "ideia de que tais sistemas repercutem com grande força nos currículos escolares, bem como transformam paulatinamente a cultura escolar" (SANTOS, 2013, p. 109) está presente na escola investigada. Essa mudança na cultura escolar pode ser expressa na necessidade de avaliar as crianças que ainda estão em processo de alfabetização. Como afirmam Catani e Gallego (2009) faz parte da cultura escolar a ideia de que "nos dois primeiros anos, quase sempre, há um número menor de provas por se alegar que as crianças estão sendo alfabetizadas" (CATANI; GALLEGO, 2009, p. 27). Porém, na escola investigada em que opera o dispositivo de antecipaşão da alfabetização, era preciso avaliar desde o primeiro ano. As avaliações sistêmicas operacionalizam no currículo do primeiro ano o procedimento da avaliaşão formal, mesmo para crianças que estão iniciando a sua inserção no Ensino Fundamental. Ainda que, no momento da reunião a professora da turma pesquisada se posicione contrariamente ao treino dos/as alunos/as, as avaliações trimestrais realizadas com os/as alunos/as mostram certo alinhamento em relação ao que está estabelecido nas avaliações sistêmicas. Em dado momento, ao explicar como deve ser a prova, a docente diz: "Vamos fazer igual a que veio da prefeitura", referindo-se à avaliação diagnóstica enviada pela Secretaria Municipal de Ensino no início do ano (Diário de campo, 25/04/2013).

As questões formuladas também se aproximam bastante daquelas que poderiam ser organizadas com base na matriz de referência da Provinha Brasil ${ }^{8}$. Assim, a primeira questão formulada refere-se a um ditado de letras, que visa verificar se as crianças são capazes de "Reconhecer letras", tal como estabelecido no primeiro descritor da matriz (BRASIL, 2011). O reconhecimento e a contagem do número de sílabas de determinada palavra (consciência silábica), que correspondem aos descritores 2 e 3 da matriz também se apresentam nas questões, bem como a leitura de palavras estabelecida no quarto descritor.

Questões relativas aos outros descritores também estão presentes nas avaliações das crianças, tais como "Ler frases" e "Identificar a finalidade de um texto". Cabe registrar também que as questões são de múltipla escolha, tal como ocorre nas avaliações sistêmicas. Assim, ainda que não se apoie explicitamente o treino para as questões da avaliação, nota-se como elas influenciam o currículo escolar. Se em outras pesquisas, como aquela desenvolvida por Morais (2012b), constatou-se "a baixa familiaridade dos aprendizes com o formato dos itens" (MORAIS, 2012b, p. 561), na escola investigada, verificamos o oposto. Tanto nas provas desenvolvidas como nas atividades cotidianas, eram comuns questões no formato "múltipla escolha". Assim, se no contexto pesquisado por Morais (2012b) é possível afirmar que "parece ingênuo atribuir a um exame externo, como a Provinha, o poder de, sem mais, fazer curriculo, de induzir os professores, a priorizarem o ensino de determinados conteúdos ou habilidades" (MORAIS, 2012b, pp. 567-568, grifos do autor), na escola investigada na pesquisa que dá base a este artigo, fica evidente o contrário.

O currículo e as ações docentes são conduzidos em função da avaliação. Ela é um elemento que "não apenas nos distribui segundo infinitos critérios, como, também, tanto nos subjetiva quanto determina nossas identidades" (VEIGA-NETO, 2013, p. 168). A avaliação subjetiva as docentes, que organizam suas práticas conforme o que está estabelecido nessas avaliações. Por meio desse processo, subjetiva também os/as alunos/as que vivem esse currículo.

\footnotetext{
${ }^{8}$ A Provinha Brasil é uma avaliação que tem como objetivo "investigar o desenvolvimento das habilidades relativas à alfabetização e ao letramento em Língua Portuguesa e Matemática, desenvolvidas pelas crianças matriculadas no $2^{\circ}$ ano do ensino fundamental das escolas públicas brasileiras" (Disponível em <http://provinhabrasil.inep.gov.br>. Acesso em 23/09/2015)
}

Práxis Educativa, Ponta Grossa, p. 795-811, v. 11, n. 3, set./dez. 2016 Disponível em: <http://www.revistas2.uepg.br/index.php/praxiseducativa $>$ 
Afinal, se considerarmos que o currículo atua no processo de subjetivação, as intervenções feitas nele, inspiradas pelas avaliações sistêmicas, também subjetivam os alunos.

A avaliação funciona também "na articulação entre o nível da coletividade e o nível da individualidade" (VEIGA-NETO, 2013, p. 168). Com relação à coletividade, a avaliação expressa os ideais que se quer para a educação, em termos de órgãos estatais. Com relação à individualidade, ela controla os atos mínimos a serem realizados pelos/as alunos/as. Assim, ela opera tanto no governo de Estado como no governo dos outros e de si. Exige-se dos/as alunos/as uma série de cuidados para que sejam bem-sucedidos nas avaliações, mesmo que ainda não sejam aquelas que servem como avaliação sistêmica. Dessa maneira, um dia antes da última avaliação do ano, a professora recomenda:

"Olhem se não está faltando material, confiram tudinho na mochila. Tomar um banho gostoso antes de vir pra escolar. Comer bem, nada gorduroso, não vir pra escola sem almoçar porque o dia que a gente não come direito, a cabeça não funciona. [...] Passem uma manhã tranquila, sem correr muito, não façam coisas muito agitadas" (Diário de campo, 19/11/2013).

A lógica avaliativa se estende para além dos momentos da avaliação. Ela passa a afetar outros âmbitos da vida infantil, exigindo determinados cuidados para expressar aquilo que sabem em avaliações. Em função do dispositivo de antecipação da alfabetização torna-se necessário controlar outros âmbitos da vida, a fim de que as crianças possam demonstrar que já estão alfabetizadas. Isso se torna importante também porque permite que a busca por "bom desempenho" nas avaliações sistêmicas seja alcançada. O currículo envolve-se, assim, com o governo dos/as infantis e docentes que vivenciam essas práticas avaliativas.

\section{Considerações finais}

A inserção das crianças de seis anos no Ensino Fundamental levantou uma série de debates e preocupações, como questões de estrutura física das escolas, formação docente para trabalhar com crianças que anteriormente estavam na educação infantil, definição do currículo desse ano escolar, estratégias de transição entre a educação infantil e o ensino fundamental e o lugar da brincadeira e do lúdico nas práticas desenvolvidas. Por um lado, trata-se de uma forma de "oportunizar às crianças das escolas públicas, geralmente provenientes dos setores de mais baixa renda da população, maior igualdade na idade de acesso à educação escolar" (SANTOS; VIEIRA, 2006, p. 777). Por outro, discute-se a necessidade de pensar em um currículo diferenciado para o primeiro ano, currículo esse que não seja uma cópia daquele realizado em anos anteriores, já que "a escola deve assegurar um currículo adequado às novas exigências de aprendizagens dessas crianças" (BRASIL, 2009, p. 23). Na escola investigada na pesquisa que deu base a este artigo, porém, o que se viu é que, muitas vezes, esse currículo era definido pelas questões relativas à alfabetização, mediadas pela prática da avaliação.

O direito ao acesso à educação também focava, de forma mais intensa, a aprendizagem da língua escrita, deixando de lado o "desenvolvimento de diversas atividades simbólicas, tais como desenho, brincadeira e diferentes formas de linguagem" (NOGUEIRA; CATANANTE, 2011, p. 185). Havia, assim, um predomínio do ensino da leitura e escrita em relação aos outros saberes e conhecimentos, evidência do funcionamento do dispositivo de antecipação da alfabetią̧ăão nesse currículo. Para garantir que, até o final do primeiro ano, as crianças saibam ler e escrever, priorizam-se saberes, conhecimentos e práticas que garantem a aquisição da língua escrita.

Práxis Educativa, Ponta Grossa, p. 795-811, v. 11, n. 3, set./dez. 2016 Disponível em: <http://www.revistas2.uepg.br/index.php/praxiseducativa> 
Nesse processo, a avaliação assume um papel importante, já que era ela que definia se a alfabetização havia sido efetivada. Ao longo do texto, procuramos evidenciar como a avaliação articulava-se a diferentes discursos para acionar procedimentos, técnicas e práticas que visavam à condução das condutas infantis e docentes e à produção da criança alfabetizada. A avaliação serve, assim, para governar aqueles/as que vivem o currículo. Ela também - sobretudo na modalidade da avaliação sistêmica - serve para definir o que é ensinado e como as atividades devem ser conduzidas. Nesse processo, o currículo também priorizava aqueles aspectos presentes nas avaliações sistêmicas. Como nos anos iniciais do Ensino Fundamental as avaliações sistêmicas priorizam a Língua Portuguesa e a Matemática, esses saberes têm mais espaço no currículo.

Se retomarmos as perguntas com as quais iniciamos este artigo, podemos perceber como há grande influência da avaliação no currículo do primeiro ano, tanto nas práticas que se consolidam, como nos conhecimentos e saberes disponibilizados aos/às alunos/as. Percebemos também como discursos variados sobre avaliação chegam ao currículo escolar, transmutando as teorias em práticas cotidianas que visam à produção de determinado tipo de sujeito. Por fim, as práticas avaliativas inserem as crianças e as docentes em determinadas relações de poder-saber que, vinculadas ao dispositivo de antecipação da alfabetiz̧ação, visam à condução de suas condutas.

Além disso, a avaliação se expandia para outros âmbitos da vida dos/as alunos/as, incluindo aí técnicas de si que eles/as deveriam operar para modificar-se e adequar-se à lógica escolar. Nesse sentido, um currículo que opera com a lógica avaliativa atua na produção de sujeitos que estão em processo constante de avaliação. Por meio das práticas avaliativas cotidianas (como os ditados), da autoavaliação para modificar o comportamento e das avaliações sistêmicas, constrói-se um intrincado processo de governo da vida, que passa pelas esferas estatais, pelas práticas diárias de sala de aula e atinge o âmbito da vida de cada criança e de cada docente. Um currículo orientado por aquilo que se espera nas avaliações e em normas definidas pelas teorias $p s i$, demanda, por meio do dispositivo de antecipação da alfabetização, uma criança que seja alfabetizada, bem-comportada e que saiba demonstrar seus saberes desde cedo por meio de testes padronizados. Demanda, ainda, uma professora que saiba coordenar suas práticas conforme esses princípios. Por meio desses dois processos, o currículo se submete às lógicas avaliativas. Saberes e conhecimentos priorizados nas avaliações se constituem no cerne das práticas de sala de aula. A avaliação orienta os modos de ser e agir no currículo escolar. Dessa forma, as crianças e as professoras são inseridas, desde o primeiro ano do Ensino Fundamental em uma lógica avaliativa que perpassa diferentes aspectos de sua vida, que atua diretamente na gestão de suas vidas escolares e privadas.

\section{Referências}

BRASIL. Ensino Fundamental de nove anos: passo a passo do processo de implantação. Brasília: MEC/SEB. 2009.

BRASIL. Provinha Brasil: Matriz de Referência para Avaliação da Alfabetização e do Letramento Inicial. Brasília: MEC/INEP, 2011. Disponível em: <http://download.inep.gov.br/download/provinhabrasil/2011/matriz_provinha_leitura.pdf>. Acesso em: 23 set. 2015.

CATANI, D. B.; GALLEGO, R. C. Avaliação. São Paulo: Editora Unesp, 2009. 
CHARTIER, A. M. Ensinar a ler e escrever, entre teoria e prática. Semana da Educação, 2010. Disponível em: < revistaescola.abril.com.br/pdf/texto-anne-marie-chartier.pdf>. Acesso em: 22 set. 2015.

CHARTIER, A.M. Ditado. In: UNIVERSIDADE FEDERAL DE MINAS GERAIS (UFMG). Faculdade de Educação (FaE). Centro de Alfabetização, Leitura e Escrita (Ceale). Glossário Ceale: termos de alfabetização, leitura e escrita para educadores. Belo Horizonte, 2014. Disponível em: <http://ceale.fae.ufmg.br/app/webroot/glossarioceale/verbetes/ditado>. Acesso em: 22 set. 2015.

CORAZZA, S. Currículo e política cultural da avaliação. Educação e Realidade, Porto Alegre, v. 20, n. 1, p. 47-59, jul/dez. 1995.

CORAZZA, S. Olhos de poder sobre o currículo. Educação e Realidade, Porto Alegre, v. 21, n. 1, p. 46-69, 1996.

CORAZZA, S. O que quer um currículo: pesquisas pós-críticas em educação. Petrópolis: Vozes, 2001.

DELEUZE, G. Controle e devir. In: DELEUZE, G. Conversações - 1972-1990. São Paulo: Editora 34, 1992a. p. 209-218.

DELEUZE, G. Um retrato de Foucault. In: DELEUZE, G. Conversações - 1972-1990. São Paulo: Editora 34, 1992b. p. 127-147.

FERNANDES, C.; FREITAS, L. Currículo e avaliação: indagações sobre o currículo. Brasília: Ministério da Educação, Secretaria de Educação Básica, 2007. p. 17-39.

FERREIRO, E. A representação da linguagem e o processo de alfabetização. Cadernos de Pesquisa, São Paulo, n. 52, p. 7-17, fev. 1985.

FERrEIRO, E.; TEBEROSKY, A. Psicogênese da língua escrita. Porto Alegre: Artes Médicas, 1985.

FOUCAULT, M. Arqueologia do saber. Petrópolis: Vozes, 1972.

FOUCAULT, M. Verdade e subjetividade. Revista de Comunicação e Linguagem. Lisboa, n. 19, p. 203-223, 1993.

FOUCAULT, M. O sujeito e o poder. In: DREYFYS H. \& RABINOW, P. Michel Foucault: Uma trajetória filosófica para além do estruturalismo e da hermenêutica. Rio de Janeiro, Forense, 1995. p. 231-249.

FOUCAULT, M. Resumo dos Cursos do Collège de France. Rio de Janeiro: Zahar, 1997.

FOUCAULT, M. Vigiar e Punir. Petrópolis: Vozes, 1999.

FOUCAULT, M. Sobre a história da sexualidade. In: MACHADO, R. Microfísica do poder. Rio de Janeiro: Graal, 2000. p. 243-276. 
FOUCAULT, M. 1984 - Foucault. In: FOUCAULT, M. Ditos e escritos V: Ética, sexualidade, política. Rio de Janeiro: Forense, 2004. p. 234-239.

HOFFMANN, J. Avaliação: mito e desafio. Porto Alegre: Mediação, $2006 a$.

HOFFMANN, J. Avaliação mediadora: uma prática em construção da pré-escola à universidade. Porto Alegre: Mediação, 2006b.

JORBAN, J.; SANMARTIN, M. A função pedagógica da avaliação. In: BALLESTER, M.; BATALLOSO, J. Avaliação como apoio à aprendizagem. Porto Alegre: Artmed, 2003. p. 2345.

LARROSA, J. Tecnologias do eu e educação. In: SILVA, T. T. (Org.). O sujeito da educação: estudos foucaultianos. Petrópolis: Vozes, 1994.

LUCKESI, C. Avaliação da aprendizagem escolar. São Paulo: Cortez, 1997.

MACHADO, R. Introdução: por uma genealogia do poder. In: MACHADO, R. (Org.). Microfísica do poder. Rio de Janeiro: Graal, 2000.

MORAIS, A. G. Sistema de escrita alfabética. São Paulo: Melhoramentos, 2012a.

MORAIS, A.G. Políticas de avaliação da alfabetização: discutindo a Provinha Brasil. Revista Brasileira de Educação, Rio de Janeiro, v. 17, n. 51, p. 551-572, set./dez, 2012b. DOI: 10.1590/s1413-24782012000300004

MOREIRA, A. F. M. Os Parâmetros Curriculares Nacionais em questão. Educação e Realidade, Porto Alegre, v. 21, n. 1, p. 9-22, 1996.

NOGUEIRA, A. L.; CATANANTE, I. Trabalho docente e desenvolvimento das atividades simbólicas: considerações para o ensino fundamental de nove anos. Educação \& Pesquisa. São Paulo, v. 37, n. 1, p. 175-190, jan./abr. 2011. DOI: 10.1590/S1517-97022011000100011

PARAÍSO, M. O currículo entre a busca por "bom desempenho" e a garantia das diferenças. In: DALBEN, A.; DINIZ, J.; LEAL, L. SANTOS, L. (Org.). Convergências e tensões no campo da formação e do trabalho docente: currículo, ensino de educação física; ensino de geografia; ensino de história; escola, família e comunidade. Belo Horizonte: Autêntica, 2010a. p. 132-152.

PARAÍSO, M. Currículo e Formação Profissional em Lazer. In: ISAYAMA, H. (Org.). Lazer em estudo: currículo e formação profissional. Campinas: Papirus, 2010b. p. 27-58.

PARAÍSO, M. Raciocínios generificados no currículo escolar e possibilidades de aprender. In: LEITE C.; PACHECO, J. A.; MOREIRA, A. F.; MOURAZ, A. (Org.). Políticas, fundamentos e práticas do currículo. Porto: Porto Editora, 2011. p. 147-160.

ROSE, N. Inventando nossos eus. In: SILVA, T. T. Nunca fomos humanos: nos rastros do sujeito. Belo Horizonte: Autentica, 2001. p. 137-203.

SÁ, A. L. Recepção e uso de material escrito para formação de professor alfabetizador: um estudo de caso da Coleção Instrumentos da Alfabetização. 2010. 404 f. Tese (Doutorado em 
Educação) - Faculdade de Educação, Universidade Federal de Minas Gerais, Belo Horizonte, 2010.

SANTOS, L.; VIEIRA, L. "Agora seu filho entra mais cedo na escola": a criança de seis anos no ensino fundamental de nove anos em Minas Gerais. Educação \& Sociedade, Campinas, v. 27, n. 96, p. 775-796, out. 2006. DOI: 10.1590/S0101-73302006000300008

SANTOS, L. As duas faces da avaliação. In: FAVACHO, A.; PACHECO, J.; SALES, S. (Orgs.). Currículo, conhecimento e avaliação: divergências e tensões. Curitiba: CRV, 2013. p. 109-122.

SILVA, T. T. Currículo e identidade social: territórios contestados. In: SILVA, T. T. Alienígenas na sala de aula: uma introdução aos Estudos Culturais em Educação. Petrópolis: Vozes, 1995. p. 190-207.

SILVA, T. T. A produção social da identidade e da diferença. In: SILVA, T. T. Identidade e Diferença. Petrópolis: Vozes, 2000. p. 73-102.

SILVA, T. T. Documentos de identidade: uma introdução às teorias do currículo. Belo Horizonte: Autêntica, 2001.

SOUZA, S. Possíveis impactos da avaliação externa no currículo escolar. In: ROSA, D. SOUZA, V. (orgs.). Políticas organizativas e curriculares, educação inclusiva e formação de professores. Rio de Janeiro: DP\&A, 2002. p. 23-38.

VEIGA-NETO, A. Delírios avaliatórios: o currículo desvia para a direita ou um farol para o currículo. In: FAVACHO, A.; PACHECO, J.; SALES, S. (Orgs.). Currículo, conhecimento e avaliação: divergências e tensões. Curitiba: CRV, 2013. p. 155-175.

Recebido em 01/12/2015

Versão corrigida recebido em 17/04/2016

Aceito em 10/05/2016 